\title{
PHYTOPLANKTON FUNCTIONAL GROUPS AND THEIR RELATIONSHIP WITH ENVIRONMENTAL FACTORS IN A EUTROPHIC AND HIGH-ALKALINITY LAKE IN THE COLD REGIONS OF NORTHERN CHINA
}

\author{
LI, X. C. - SUN, X. - MA, C. X. ${ }^{*}-$ YU, H. X. \\ Department of Ecology, College of Wildlife and Protected Area, Northeast Forestry University, \\ Harbin 150040, China \\ (e-mail: Lixingchun0612@126.com-Li, X. C.; phone: +86-186-1248-9321) \\ ${ }^{*}$ Corresponding authors \\ e-mail: mch007@vip.163.com; phone: +86-180-0366-8291 (Ma, С.X.) \\ e-mail: china.yhx@163.com; phone: +86-131-0096-0911 (Yu, H. Х.)
}

(Received $1^{\text {st }}$ Sep 2020; accepted $18^{\text {th }}$ Dec 2020)

\begin{abstract}
The investigation of phytoplankton was carried out from May to October month by month in 2018 in Hulun Lake, north China. Our purpose is to explore the community structure characteristics of phytoplankton by using the method of functional groups, combined with the monitoring results of water environmental factors, discussed the correlation between them in this special lake with high alkalinity, turbidity and eutrophication, so as to further explore the mechanisms of cyanobacteria bloom. Altogether 21 functional groups were identified, including 7 predominant functional groups. The predominant functional groups demonstrated strong spatio-temporal variations. It should also be noted that group H1 and $\mathrm{M}$ were the main culprits for the cyanobacteria bloom in the lake. Redundancy and Pearson analysis revealed that WT, DO, TP and TN were the most significant environmental factors controlling the distribution of phytoplankton functional groups. Furthermore, this study also evaluated the water quality in Hulun Lake by using Q index which shows it in a "medium" state. In a word, our results evidenced that a timely water environment dynamic can be reflected by monitoring the phytoplankton in Hulun Lake, which is also a superb way for the real-time monitoring of cyanobacteria bloom in this area.
\end{abstract}

Keywords: cyanobacteria bloom, spatio-temporal succession, nutrient, ecological status, multivariate analysis, growth strategy

\section{Introduction}

Water is the source of life. Freshwater resources which is available to human beings accounting for $0.26 \%$ of the global water resources. Among them, lake has provided more than half of drinking water resources for urban in inland China. It also plays a pivotal role in regulating river runoff, developing irrigation, multiplying aquatic organisms and improving regional ecological environment. Therefore, the protection of lake has always been one of the most significant themes in the process of protecting the global water environment. However, under the joint promotion of climate change and human activities, lakes have undergone various changes in recent years. Among them, the issue of eutrophication has been highly valued.

As an international environmental problem, eutrophication of the water body is threatening the ecological security of water areas all over the world. Eutrophication refers to a phenomenon where the water body is enriched in a large amount of nutrients like nitrogen and phosphorus, resulting in abnormal reproduction of algae and other aquatic organisms, ultimately leading to the deterioration of lake water quality, inhibition and destruction of both water ecosystem and self-purification ability. Eutrophication will increase the content of organic matter in water to a certain extent, and even lead to harmful 
algal blooms (Paerl, 1988). However, a large-scale of cyanobacteria bloom will foul waterways and water intakes, disrupt food webs, fuel hypoxia and produce secondary metabolites which are toxic to water consumers and users, including zooplankton, fish, shellfish, cattle, domestic pets, and human (Shang, 2017). Cyanobacterial bloom dynamics have been frequently reported in lake (Solis et al., 2018; Rose et al., 2019) which associated with many environmental factors, including low turbulence, low light, low ratio of euphotic zone to mixing zone and high temperature. Among them, temperature plays a considerable role. Generally speaking, the area of cyanobacteria bloom is mainly concentrated in tropical and subtropical areas. Therefore, the research on cyanobacteria bloom is also mainly concentrated in these areas. For domestic in China, the research is mainly concentrated in the area with high temperature, such as Taihu Lake and Chaohu Lake (Chuai et al., 2011; Zhang et al., 2016) which in the south of China. The research on cyanobacteria bloom region which in the north cold area is almost none.

Phytoplankton is an important primary producer of aquatic ecosystems and a major component of the aquatic food chain. It has become a pivotal indicator species which can reflect the water quality because of its rapid regeneration and sensitivity to environmental changes (Camp et al., 2015; Zwart et al., 2015). Therefore, the study of phytoplankton is helpful for us to evaluate the water quality and the nutritional status of water body. Many methods have been developed to evaluate water quality by using different idexes of phytoplankton, such as abundance, biomass and community composition (Birk et al., 2012). However, these traditional methods ignore the environmental and ecological characteristics of phytoplankton population, so it exposes many deficiencies in specific application. Reynolds et al. (2002) proposed the theory of phytoplankton functional group. Padisák et al. (2009) supplemented and improved the theory on the basis of Reynolds. Using this method to classify phytoplankton from the perspective of ecological function, a new concept of functional group was proposed. This method is conducive to us to describe the habitat characteristics of phytoplankton more accurately, so as to predict specific life. In this paper, the functional groups of phytoplankton are studied to explore the community distribution of phytoplankton in the environment.

The growth of phytoplankton will be affected by various environmental factors, such as water temperature, light availability, acid and alkali. Therefore, the species and biomass of phytoplankton vary greatly under different environmental conditions. Hulun Lake is a typical alkaline eutrophication water body in the cold area of north China. In recent years, a series of ecological problems caused by serious eutrophication of water body have been emerging, such as seriously cyanobacteria bloom occurs in summer with the highest temperature every year, miniaturization of zooplankton and fish, etc., which have attracted great attention of the state and government. As phytoplankton is increasingly common used in bioassessments, studying the lake organisms in relation to abiotic factors and identifying spatial patterns of biodiversity as well as their driving mechanisms have become a major trend of ecology as basis for prioritizing global and regional conservation efforts (Myers et al., 2000; Wang et al., 2016c). Therefore, this paper takes Hulun Lake as the research object, further studies phytoplankton and the relationship between phytoplankton and environmental factors by means of functional groups, reveals which environmental factors have influence on the distribution of phytoplankton functional groups by means of RDA and Pearson and comprehensively evaluates the water environment state of Hulun Lake basin with Q index, so as to explore the temporal and spatial distribution mechanism of cyanobacteria bloom. In response to the call of the state, it also provides a new monitoring method and important theoretical 
basis for the study of phytoplankton functional groups in the high alkalinity water body which in cold region.

\section{Materials and methods}

\section{Investigation area and sampling sites description}

Hulun Lake $\left(48^{\circ} 31^{\prime}-49^{\circ} 20^{\prime} \mathrm{N}, 116^{\circ} 58^{\prime}-117^{\circ} 48^{\prime} \mathrm{E}\right)$, which is also known as Dalai Lake, lies in the hinterland of Hulunbuir prairie, Inner Mongolia, China. It is the fifth largest freshwater lake in China with the size of $2339 \mathrm{~km}^{2}$ with the deepest water level of $9 \mathrm{~m}$. Mean annual precipitation is $247-319 \mathrm{~mm}$, and $80-86 \%$ of the annual precipitation falls in June to September. The lake is covered with $1 \mathrm{~m}$ of ice from early November to late April. Except for rainfall and groundwater, the water supply of Hulun Lake mainly depends on direct surface runoff. The main rivers flowing into Hulun Lake include Crulen River and Orshen River which between Baikal Lake and Hulun Lake. Moreover, Hailar River is one of the most important water sources of Hulun Lake through the project of "Diversion of rivers into lake". And the Xinkai River which locates in the northeast of Hulun Lake is a throughput river regulating the water level of Hulun Lake. Hulun Lake Basin is a crucial ecological barrier in the north and plays an important ecological role in regulating the climate, conserving water resources, preventing desertification, and maintaining the balance of the grassland ecosystem.

According to the ecological environment characteristics of the Hulun Lake, following the principle of uniform distribution of sampling points, a total of 10 sampling points (Table 1, Fig. 1) are arranged in the lake body of Hulun Lake, including four sampling points specially set at the entrance of the lake due to the special relationship with the surrounding four rivers ( $1^{\#}$-Xinkai River Estuary; $4^{\#}$-Crulen River Estuary; $6^{\#}$-Orshenn River Estuary; $7^{\#}$-Hailar River Estuary). In addition, there are also $2^{\#}-3^{\#}$ located in the

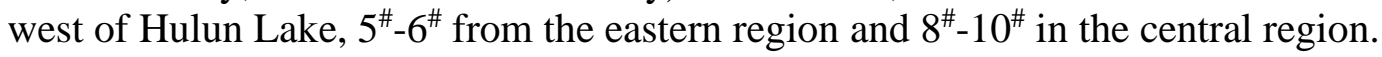

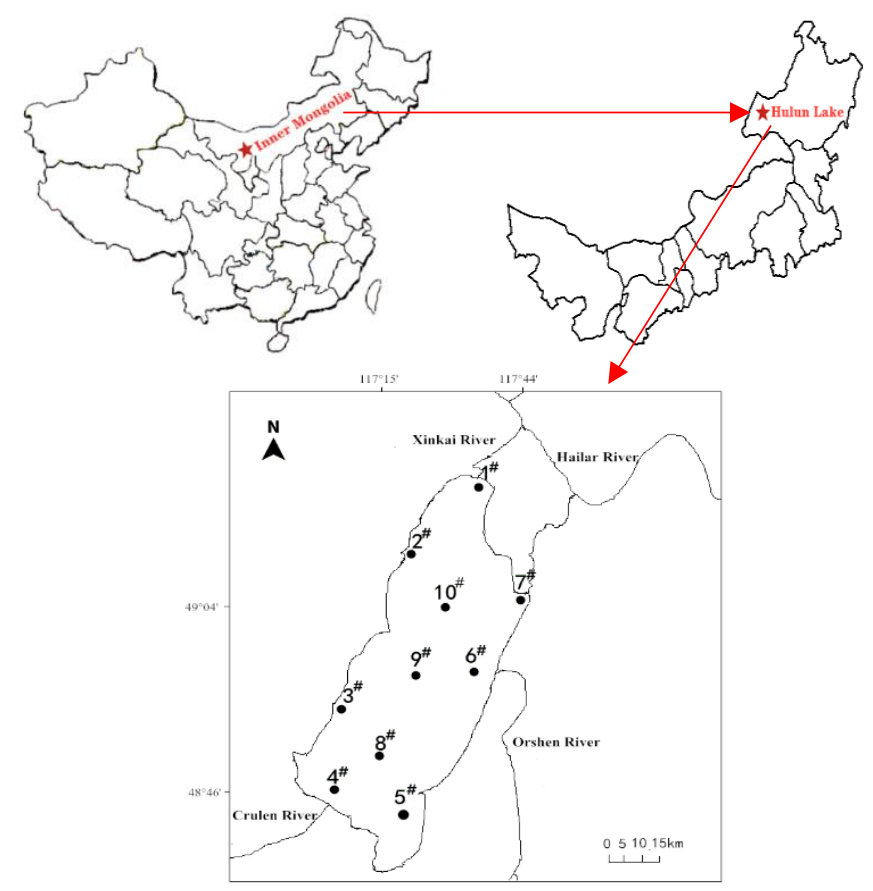

Figure 1. Location of the study area and the sampling points in Hulun Lake 


$$
\text { - } 1552 \text { - }
$$

Table 1. Ten sampling sites coordinates in Hulun Lake

\begin{tabular}{c|c|c}
\hline Sampling sites & Latitude & Longitude \\
\hline $1^{\#}$ & $\mathrm{~N} 49^{\circ} 18^{\prime} 10.61^{\prime \prime}$ & $\mathrm{E} 117^{\circ} 38^{\prime} 40.75^{\prime \prime}$ \\
$2^{\#}$ & $\mathrm{~N} 49^{\circ} 09^{\prime} 36.88^{\prime \prime}$ & $\mathrm{E} 117^{\circ} 25^{\prime} 24.04^{\prime \prime}$ \\
$3^{\#}$ & $\mathrm{~N} 48^{\circ} 55^{\prime} 06.01^{\prime \prime}$ & $\mathrm{E} 117^{\circ} 08^{\prime} 36.90^{\prime \prime}$ \\
$4^{\#}$ & $\mathrm{~N} 48^{\circ} 46^{\prime} 44.12^{\prime \prime}$ & $\mathrm{E} 117^{\circ} 04^{\prime} 52.88^{\prime \prime}$ \\
$5^{\#}$ & $\mathrm{~N} 48^{\circ} 43^{\prime} 15.38^{\prime \prime}$ & $\mathrm{E} 117^{\circ} 17^{\prime} 45.55^{\prime \prime}$ \\
$6^{\#}$ & $\mathrm{~N} 48^{\circ} 58^{\prime} 55.21^{\prime \prime}$ & $\mathrm{E} 117^{\circ} 37^{\prime} 26.59^{\prime \prime}$ \\
$7^{\#}$ & $\mathrm{~N} 49^{\circ} 06^{\prime} 44.45^{\prime \prime}$ & $\mathrm{E} 117^{\circ} 44^{\prime} 53.27^{\prime \prime}$ \\
$8^{\#}$ & $\mathrm{~N} 48^{\circ} 49^{\prime} 51.94^{\prime \prime}$ & $\mathrm{E} 117^{\circ} 15^{\prime} 51.25^{\prime \prime}$ \\
$9^{\#}$ & $\mathrm{~N} 48^{\circ} 57^{\prime} 32.13^{\prime \prime}$ & $\mathrm{E} 117^{\circ} 25^{\prime} 49.68^{\prime \prime}$ \\
$10^{\#}$ & $\mathrm{~N} 49^{\circ} 04^{\prime} 07.70^{\prime \prime}$ & $\mathrm{E} 117^{\circ} 33^{\prime} 07.93^{\prime \prime}$ \\
\hline
\end{tabular}

\section{Sampling collection and analysis}

Many studies focus on how different environmental and spatial parameters, such as hydrological, physical and chemical ones (Isabwe et al., 2018; Wu et al., 2018) shape phytoplankton community. This approach may result in inaccurate prioritizations (Wu et al., 2018). So, there is a need for a parallel monitoring of the biota and the number of environmental drivers synchronously in space and time (Belletti et al., 2017; Latinopoulos et al., 2020). Different types of phytoplankton have different requirements for the environment. The environmental conditions of a certain season are more suitable for some types, while others are not. For phytoplankton, not only will the species composition change in different seasons, but also the biomass of phytoplankton will have very significant seasonal changes. In recent years, scholars have been committed to exploring the temporal and spatial succession of phytoplankton functional groups and their influencing factors. Therefore, they took samples at monthly intervals to explore their succession characteristics and further confirm which environmental factors influence the phytoplankton community structure (Yang et al., 2020; Liao et al., 2020). The monthly monitoring of physicochemical indices, especially WT and nutrients, is more effective in analyzing the environmental thresholds required for the cyanobacteria bloom which could be used to forecast the rapid formation of a cyanobacteria bloom. Therefore, we use the method of synchronous monitoring of phytoplankton and physicochemical index, took water samples at monthly intervals in ten sampling sites from May to October in 2018. Physical and chemical indicators such as water temperature (WT), $\mathrm{pH}$ and conductivity (Cond) are measured directly by a portable multi-probe (YSI 6600, YSI Inc., USA) in sampling site. Secchi disk is used for the determination of water transparency (SD). Analysis of nutrients like total nitrogen (TN) and total phosphorus (TP) requires that we take water samples back to laboratory and then measured by oxidation with alkaline persulfate and persulfate acid as described by Costa et al. (2009). In addition, we used the Chinese standard methods proposed by Ministry of Environmental Protection of People's Republic of China (MEP, 2002) to determine the ammonium nitrogen $\left(\mathrm{NH}_{4}{ }^{+}-\mathrm{N}\right)$, chemical oxygen demand $\left(\mathrm{COD}_{\mathrm{Cr}}\right)$ and dissolved oxygen (DO).

Phytoplankton analysis was sampled with calibrated $1 \mathrm{~L}$ van Dorn sampler at the surface and the bottom of the water column and integrated over depth for every site, then transfer to $1 \mathrm{~L}$ phytoplankton bottle and add 10-15 $\mathrm{mL}$ Lugol's solution immediately. 
After being taken back to the laboratory, sedimented for $48 \mathrm{~h}$ then concentrated to a final volume of $30 \mathrm{~mL}$. Species were identified and counted using an inverted microscope at 400 magnification. The estimation of phytoplankton biomass is based on a method proposed by Hillebrand et al. (1999) and Chen et al. (2003) then transforming biovolume to biomass by using a formula of $1 \mathrm{~mm}^{3} / \mathrm{L}=1 \mathrm{mg} / \mathrm{L}$. The classification and determination of phytoplankton functional groups are based on Reynolds et al. (2002), Reynolds (2006), and Padisák et al. (2009).

\section{Data analysis}

After dimensionalizating the biomass data of phytoplankton functional group and environmental data other than $\mathrm{pH}$ through $\mathrm{Lg}^{(\mathrm{X}+1)}$, detrended correspondence analysis EQ showed that the lengths of gradient value were 2.622 (between 2 and 3). So after employing Monte Carlo simulation to test the significance of physico-chemical variable in explaining the phytoplankton functional groups under unrestricted model of 499 permutations. RDA (Redundancy Analysis) was used to further analyze the correlation between functional group characteristics and environmental factors. Seasonal variations of physical-chemical factors and phytoplankton biomass were tested by one-way ANOVA using the SPSS 19 software. Pearson's correlation analysis was also used to explore the relationships between phytoplankton functional groups and environmental factors. Meanwhile, the Q index using to evaluate the water quality of the lake was calculated by Equations 1 and 2 (Padisák et al., 2006). According to the different value of $\mathrm{Q}$ index, water condition can be divided into five grades: 0-1: poor ecological status; 1-2: tolerable; 2-3: medium; 3-4: good; 4-5: excellent. On the whole, statistical analysis and figures drawing was done using SPSS 17.0 (SPSS, 2008), Microsoft Excel window and Origin Pro 8.

$$
\begin{gathered}
Q=\sum_{i=1}^{n} p_{i} F \\
p_{i}=n_{i} / N
\end{gathered}
$$

In Equation 2, $n_{i}$ is the biomass of the $i$-th fuctional group, $\mathrm{N}$ is the total biomass, and $\mathrm{F}$ factor is established for each $i$-th functional group in the given lake type which shows in Table 2.

\section{Results}

\section{Seasonal variation of environmental factors}

The variation of water environmental factors in Hulun Lake are recorded in Table 2. During the investigation, most of the environmental factors displayed significant seasonal differences $(p<0.01$, by ANOVA). Water temperature (WT) got the minimum value in October $\left(6.25^{\circ} \mathrm{C}\right)$ and the maximum value in July $\left(24.13^{\circ} \mathrm{C}\right)$, this huge temperature differences had a strong impact on the growth and distribution of phytoplankton. Following the same pattern, the dissolved oxygen (DO) value fluctuated greatly $(p<0.01$, by ANOVA) with the seasons too. $\mathrm{pH}$ was always higher than 8.9 which means the whole area is alkaline. Mean conductivity (Cond) in the Hulun Lake did not vary seasonally $(p>0.05$, by ANOVA) but relative low value was recorded in August $(1522.2 \mu \mathrm{s} / \mathrm{cm})$. 
Chemical oxygen demand (COD) values were higher in autumn (September and October) and lower in Spring (May). The change of ammonia nitrogen $\left(\mathrm{NH}_{4}{ }^{+}-\mathrm{N}\right)$ value was also significant which the peak value was observed in July $(0.613 \mathrm{mg} / \mathrm{L})$. Total nitrogen (TN) showed an increasing trend from May to August. Total phosphorus (TP) fluctuated around $0.2 \mathrm{mg} / \mathrm{L}$ from May to October which indicating the severe eutrophication in Hulun Lake. Morever, statistical differences among seasons were recorded for SD too $(p<0.01$, by ANOVA), which the lowest value of SD was recorded in May $(19 \mathrm{~cm})$.

Table 2. The seasonal variations (mean \pm standard error) of environmental factors comparing by One-way ANOVA. Environmental parameters including water temperature(WT), dissolved oxygen(DO), $\mathrm{pH}$, conductivity(COND), Chemical oxygen demand(COD), $\mathrm{NH}_{4}{ }^{+} \mathrm{N}$, total nitrogen $(T N)$, total phosphorus(TP), water transparency (SD) and phytoplankton biomass

\begin{tabular}{c|c|c|c|c|c|c|c}
\hline & May & June & July & August & September & October & p-value \\
\hline $\begin{array}{c}\mathrm{WT} / \\
\left({ }^{\circ} \mathrm{C}\right)\end{array}$ & $16.27 \pm 3.05$ & $23.92 \pm 0.95$ & $24.13 \pm 0.90$ & $21 \pm 0.00$ & $14.92 \pm 1.82$ & $6.26 \pm 0.56$ & $0.000^{* *}$ \\
$\begin{array}{c}\mathrm{DO} / \\
(\mathrm{mg} / \mathrm{L})\end{array}$ & $9.56 \pm 0.43$ & $8.21 \pm 0.30$ & $7.85 \pm 0.33$ & $7.73 \pm 0.42$ & $9.92 \pm 0.65$ & $11.7 \pm 0.24$ & $0.000^{* *}$ \\
$\mathrm{pH}$ & $8.93 \pm 0.05$ & $8.93 \pm 0.05$ & $9 \pm 0.09$ & $9 \pm 0.09$ & $9.06 \pm 0.08$ & $9 \pm 0.07$ & $0.002^{* *}$ \\
$\begin{array}{c}\mathrm{COND} / \\
(\mu \mathrm{cm})\end{array}$ & $1670.2 \pm 109.05$ & $1746.4 \pm 152.76$ & $1630.8 \pm 212.2$ & $1522.2 \pm 279.78$ & $1568.5 \pm 411.78$ & $1664 \pm 126.27$ & 0.369 \\
$\begin{array}{c}\mathrm{COD} / \\
(\mathrm{mg} / \mathrm{L})\end{array}$ & $54.6 \pm 4.70$ & $74.4 \pm 24.08$ & $59 \pm 4.47$ & $78.9 \pm 19.07$ & $106.73 \pm 29.49$ & $134.5 \pm 15.13$ & $0.000^{* *}$ \\
$\begin{array}{c}\mathrm{NH}{ }^{+}-\mathrm{N} / \\
(\mathrm{mg} / \mathrm{L})\end{array}$ & $0.057 \pm 0.02$ & $0.03 \pm 0.03$ & $0.613 \pm 0.94$ & $0.105 \pm 0.07$ & $0.0496 \pm 0.01$ & $0.051 \pm 0.03$ & $0.008^{* *}$ \\
$\begin{array}{c}\mathrm{TN} / \\
(\mathrm{mg} / \mathrm{L})\end{array}$ & $1.93 \pm 1.02$ & $2.08 \pm 0.96$ & $2.12 \pm 1.11$ & $2.498 \pm 1.35$ & $1.701 \pm 0.46$ & $1.982 \pm 0.16$ & 0.559 \\
$\begin{array}{c}\mathrm{TP} / \\
(\mathrm{mg} / \mathrm{L})\end{array}$ & $0.25 \pm 0.10$ & $0.18 \pm 0.02$ & $0.255 \pm 0.04$ & $0.179 \pm 0.08$ & $0.2 \pm 0.04$ & $0.1856 \pm 0.03$ & $0.008^{* *}$ \\
$\begin{array}{c}\mathrm{SD} / \\
(\mathrm{cm})\end{array}$ & $19 \pm 8.78$ & $19.42 \pm 6.52$ & $32.25 \pm 4.96$ & $49.9 \pm 3.73$ & $40 \pm 11.29$ & $34.7 \pm 4.08$ & $0.000^{* *}$ \\
$\begin{array}{c}\mathrm{Biomass} / \\
(\mathrm{mg} / \mathrm{L})\end{array}$ & $1.54 \pm 0.52$ & $2.22 \pm 1.44$ & $2.22 \pm 1.44$ & $0.90 \pm 0.40$ & $1.84 \pm 0.48$ & $1.67 \pm 2.67$ & 0.027 \\
\hline
\end{tabular}

**The environmental factors were significantly different at the level of 0.01

\section{Phytoplankton community and functional groups}

From May to October in 2018, 86 genera belonging to 7 taxonomic categories were identified at ten sampling sites in Hulun Lake. Among them, 41 species (47.67\%) were Chlorophyta, followed by Bacillariophyta (25 species) (29.07\%), Cyanophyta (12 species) (13.95\%), Euglenophyta (3 species) (3.49\%), Chrysophyta (3 species) (3.49\%), Cryptophyta (1 species) (1.16\%) and Pyrrophyta (1 species) $(1.16 \%)$. With the passage of time, the number of species in the whole area showed a trend of August (66 species) $>$ October $(58$ species $)>\operatorname{June}(57$ species $)>$ May $(56$ species $)>\operatorname{July}(53$ species $)>$ September (50 species).

In total, phytoplankton were divided into 21 functional groups namely $\mathrm{C}, \mathrm{D}, \mathrm{E}, \mathrm{F}, \mathrm{G}$, H1, J, L0, M, MP, N, P, S1, T, TB, W1, W2, X1, X2, X3, Y (Table 3). However, 7 functional groups (J, X2, W1, F, H1, M, MP) contributing more than $10 \%$ of total phytoplankton abundance per sample were classified as dominant groups. 


$$
-1555-
$$

Table 3. Division of phytoplankton functional groups and their biomass proportion. $F$ factor corresponding with each functional group in Hulun Lake

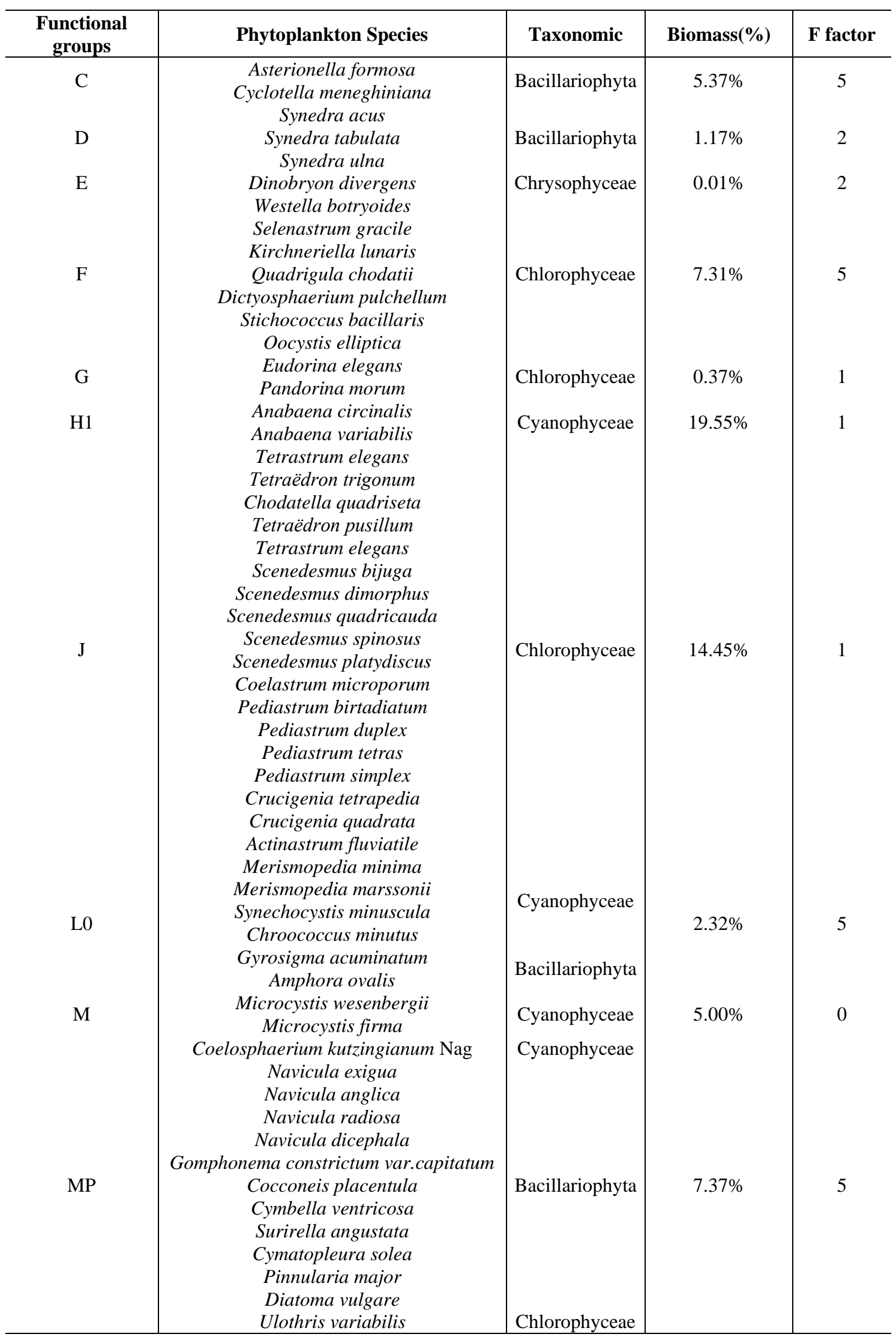




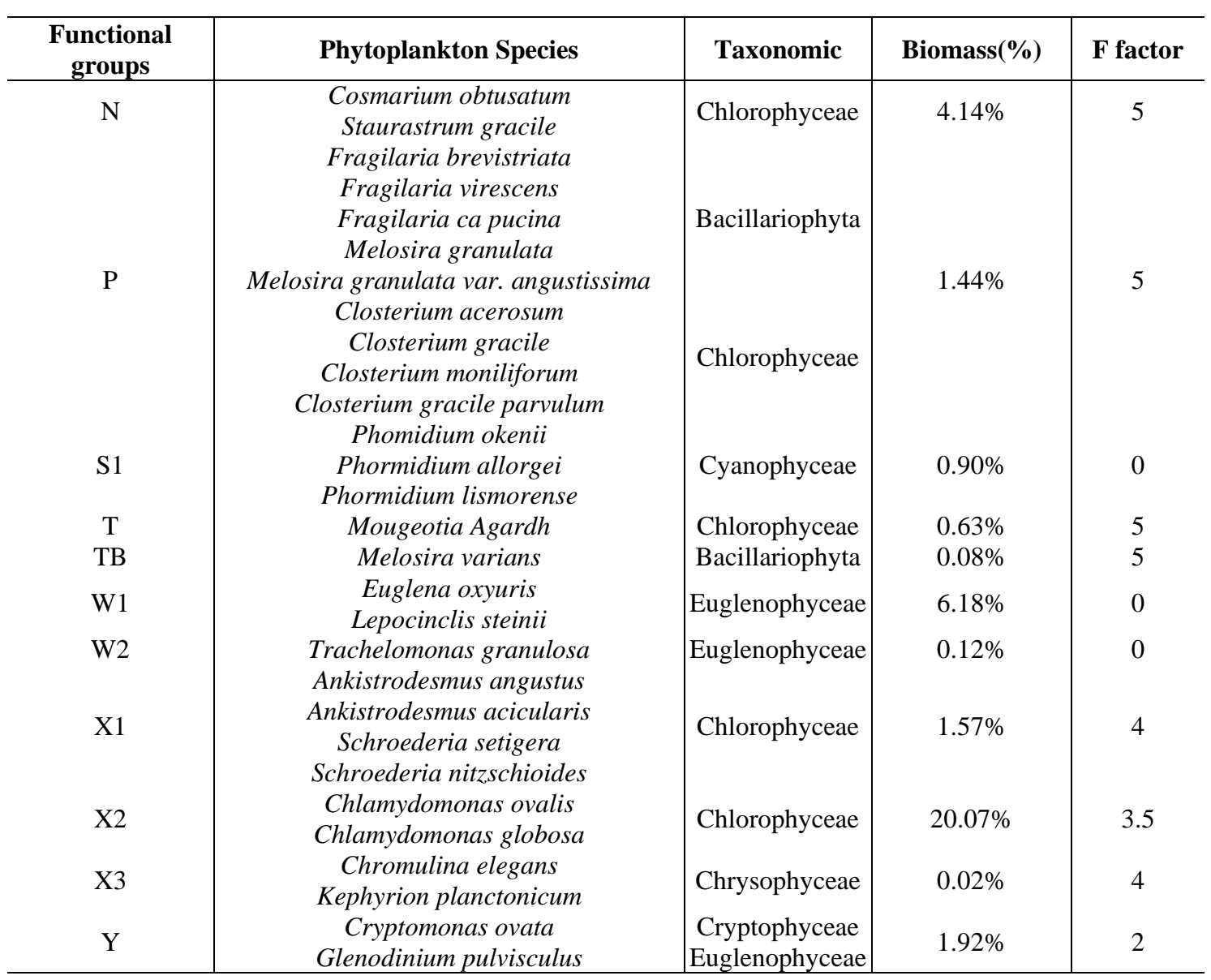

\section{Temporal and spatial variation of phytoplankton functional groups}

The biomass of phytoplankton functional groups showed seasonal and spatial variation (Fig. 2). At the beginning of the study (May), functional groups $\mathrm{J}$ and $\mathrm{X} 2$ occupied the main dominant position with the relative biomass of $29.78 \%$ and $23.14 \%$. From the perspective of the functional groups' biomass distribution at each sampling point, group $\mathrm{W} 1$ accounted for a large proportion $(46.58 \%)$ in site $9^{\#}$. Furthermore, in this month's investigation, all the dominant functional groups were distributed in all sampling points except group M. In June, the biomass of each sampling site varied greatly. The highest biomass was in site $7^{\#}(4.54 \mathrm{mg} / \mathrm{L})$ and the lowest was in site $2^{\#}(0.50 \mathrm{mg} / \mathrm{L})$. The dominant functional groups were $\mathrm{H} 1$ and $\mathrm{X} 2$. Group $\mathrm{H} 1$ showed a very high biomass in site $5^{\#}, 7^{\#}, 8^{\#}, 9^{\#}$, accounting for $63.63 \%, 49.12 \%, 53.03 \%$ and $59.50 \%$ of the total biomass of these sampling sites respectively, and the total biomass of functional group $\mathrm{H} 1$ reached the highest value $(8.59 \mathrm{mg} / \mathrm{L})$ in this month during the whole survey. In July, the dominant functional groups were $\mathrm{H} 1$ and J. Group J got the peak biomass in site $5^{\#}$ and the biomass distribution of group H1 was the largest among the site $9^{\#}$. The dominant position of these two functional groups in July indicated that eutrophication was very serious at this time. With the increasing of the temperature, the cyanobacteria boom in Hulun Lake becoming more serious. From the beginning of August, the biomass of group $\mathrm{M}$ began to increase abruptly, with $\mathrm{H} 1$ together, became the dominant functional group in August. It was noteworthy that group $\mathrm{M}$ did not distribute at $3^{\#}-7^{\#}$ sampling points, but it occupied a considerable proportion in site $1^{\#}, 2^{\#}$ and $10^{\#}$. In September, H1 functional 
group no longer occupied the dominant position, even did not distribute in site $4^{\#}$. Group $\mathrm{X} 2 / \mathrm{J}$ became the dominant functional group. X2 functional group accounting for $63.07 \%$ of the total biomass in site $3^{\#}$. Group $\mathrm{J}$ was less distributed in site $9^{\#}$ than in other sampling points. In October, the dominant functional groups were still $\mathrm{J}$ and X2. Group X2 accounted for a large proportion in site $2^{\#}, 3^{\#}, 4^{\#}$ and functional group $M$ was only distributed in site $10^{\#}$. Overall, the dominate seasonal variation of phytoplankton functional groups showed a trend of $\mathrm{J}+\mathrm{X} 2$ (May) $\rightarrow \mathrm{H} 1 / \mathrm{X} 2$ (June) $\rightarrow \mathrm{H} 1 / \mathrm{J}($ July) $\rightarrow$ $\mathrm{M} / \mathrm{H} 1$ (August) $\rightarrow \mathrm{X} 2 / \mathrm{J}($ September $) \rightarrow \mathrm{J} / \mathrm{X} 2 / \mathrm{MP}($ October).
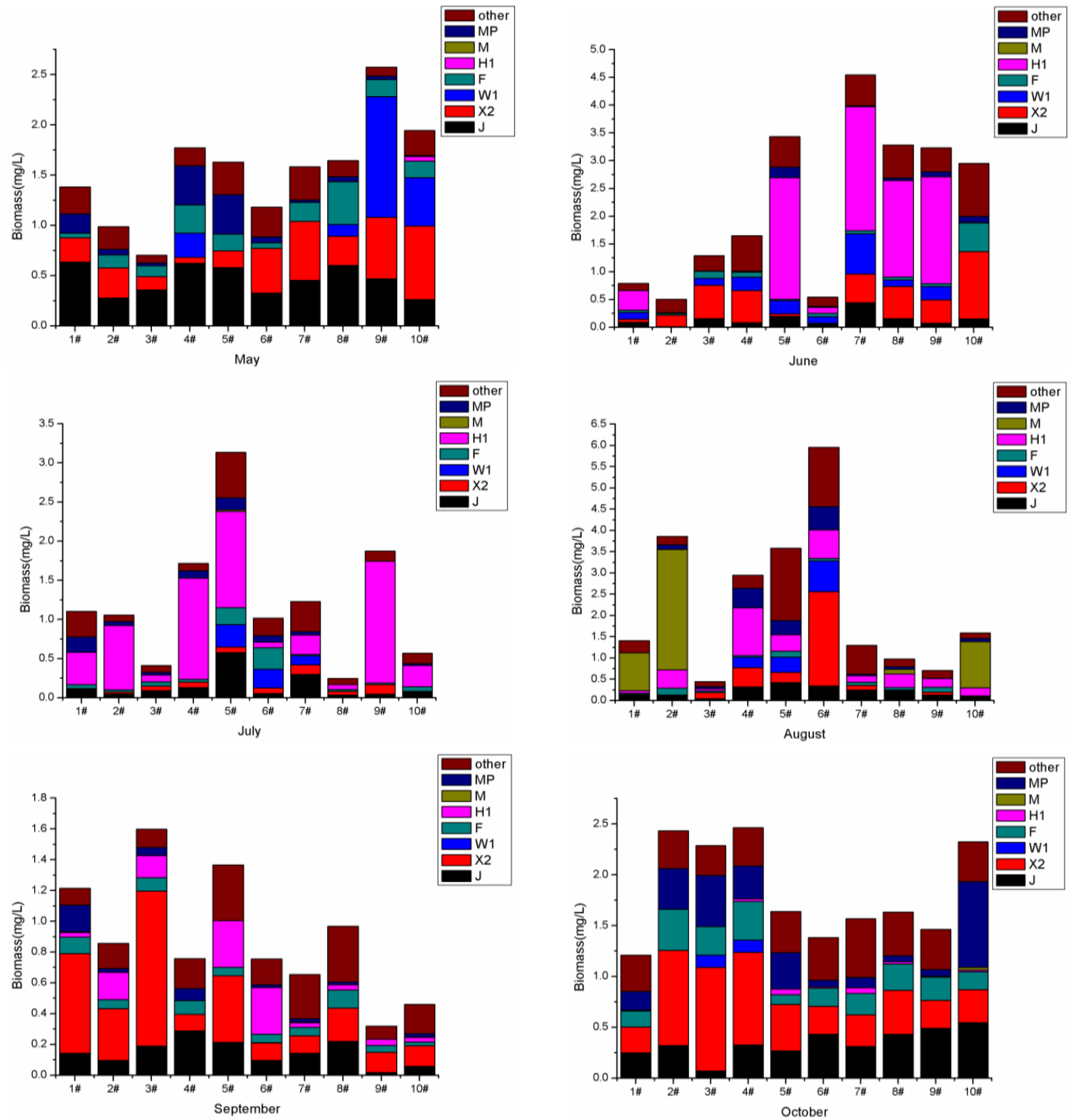

Figure 2. Temporal and spatial distribution in biomass of phytoplankton functional group

\section{$Q$ index}

According to the $\mathrm{Q}$ index monitoring ecological status of lakes recommended by Padisák et al. (2006), factor F weights for each phytoplankton functional group identified appear in Table 3. The results are showed in Fig. 3. Differences of Q index between seasons and sampling sites are very significant. 


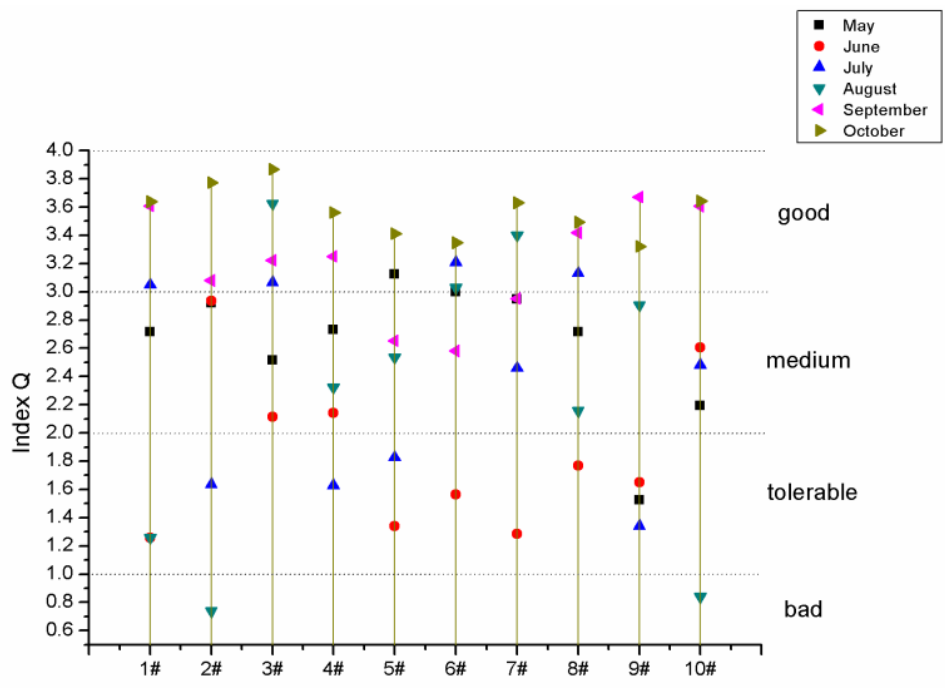

Figure 3. Ecological status evaluation by $Q$ index in Hulun Lake

During the whole investigation, the Q index fluctuated between 0.74 and 3.87, and the two sampling points with the lowest value also means having the worst water quality both appeared in August, one was in site $2^{\#}$ and the other was in site $10^{\#}$, which having a "bad" water quality. The highest value of $Q$ index was in site $3^{\#}$ in October which had the lowest TP value $(0.148 \mathrm{mg} / \mathrm{L})$. According to the comprehensive evaluation on the average value of Q index in each month, the water quality in May, July and August was the same, all of which were "medium". The water quality in the lake was "good" in September and October, while the overall water quality in June was the worst, showing a "tolerable" level. As can also be seen from Fig. 3, sampling sites which on the level of "tolerable" and "bad" were mostly occured in June, July and August when Hulun Lake was having a severe cyanobacteria boom.

\section{Correlation analysis}

Redundancy analysis (RDA) was performed to reveal the relationship between phytoplankton functional groups and environmental parameters. The analysis involved seven phytoplankton functional groups and nine physiochemical data. The eigenvalues for RDA axis 1 (0.089) and axis 2 (0.053) explained 14.2\% (axis 1: 8.9\%, axis 2: 5.3\%) of variance in phytoplankton functional groups data and $63.1 \%$ (axis 1: 44.9\%, axis 2: $26.6 \%$ ) of functional groups-environment variables (Table 4). Variables like DO (0.7076), COD (0.5238), TN (0.2717), SD (0.0596) and Cond (0.0120) were positively related to axis 1 , whereas it was negatively related with WT (-0.8493), $\mathrm{NH}_{4}{ }^{+}-\mathrm{N}(-0.3978)$ TP $(-0.1567)$ and $\mathrm{pH}(-0.0163)$. Axis 2 was positively correlated with TN (0.5188), WT (0.2698), $\mathrm{pH}(0.0981)$, COD (0.0289) and negatively correlated with TP (-0.5280), SD (-0.3698), DO (-0.3564), Cond (-0.2695) and $\mathrm{NH}_{4}{ }^{+}-\mathrm{N}(-0.0360)$ (Fig. 4).

The Pearson correlations among the biomass of the dominant phytoplankton functional groups and environmental variables are presented in Table 5. Most of phytoplankton functional groups were significantly correlated with the environmental variables. The biomass of functional $\mathrm{J}$ and $\mathrm{F}$ were all significantly positive correlated with $\mathrm{WT}(p<0.01)$ while negatively correlated with DO $(p<0.01)$. Moreover, Cond had a positive correlation with group $\mathrm{F}(p<0.05)$. Conversely, group H1 was positively correlated with $\mathrm{WT}(p<0.01)$, 
while negatively correlated with DO $(p<0.01)$. Group W1 was positively correlated with WT $(p<0.05)$, while negatively correlated with SD $(p<0.05)$. Besides, group MP was both positively correlated with DO $(p<0.05)$ and COD $(p<0.05)$, while negatively with WT $(p<0.01)$.

Table 4. CCA analysis of dominant phytoplankton functional groups and environmental factors in Hulun Lake

\begin{tabular}{c|c|c|c|c}
\hline Axes & Eigenvalues & $\begin{array}{c}\text { Speccies- } \\
\text { environment } \\
\text { correlations }\end{array}$ & $\begin{array}{c}\text { Cumulative percentage } \\
\text { variance of species } \\
\text { data\% }\end{array}$ & $\begin{array}{c}\text { Cumulative percentage } \\
\text { variance of species- } \\
\text { environment relation\% }\end{array}$ \\
\hline 1 & 0.089 & 0.581 & 8.9 & 44.9 \\
2 & 0.053 & 0.463 & 14.2 & 71.5 \\
3 & 0.036 & 0.577 & 17.8 & 89.5 \\
4 & 0.01 & 0.413 & 18.8 & 94.5 \\
\hline
\end{tabular}

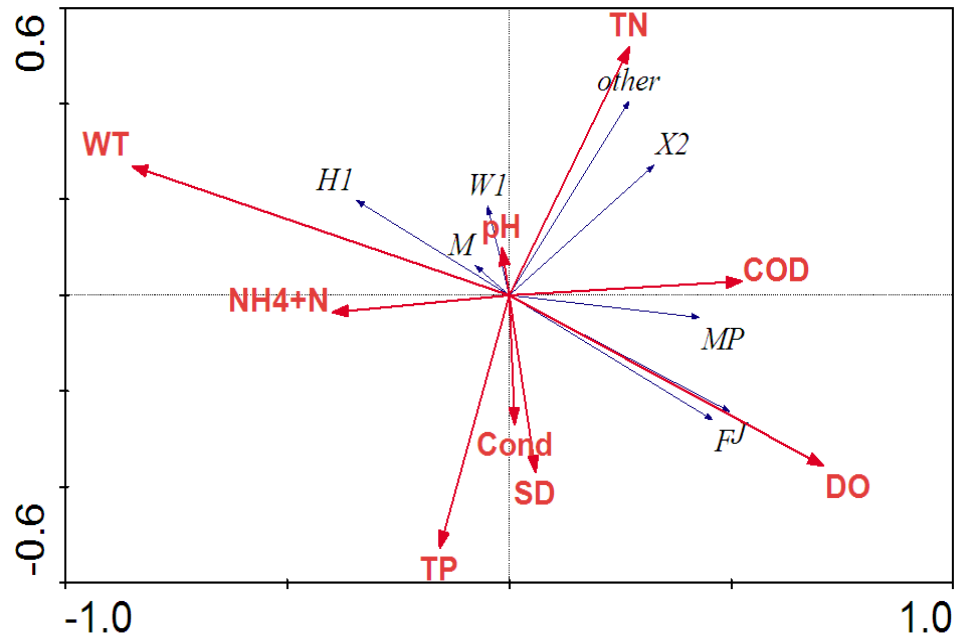

Figure 4. Redundancy analysis (RDA) ordination diagram of the dominant functional groups and physical-chemical variables in Hulun Lake

Table 5. Pearson correlation between phytoplankton functional group biomass (J, X2, Wl, F, $H 1, M, M P$, other) and environmental factors, water temperature (WT), dissolved oxygen(DO), $\mathrm{pH}$, conductivity (COND), Chemical oxygen demand (COD), $\mathrm{NH}_{4}{ }^{+}-\mathrm{N}$, total nitrogen(TN), total phosphorus(TP), water transparency (SD)

\begin{tabular}{c|c|c|c|c|c|c|c|c}
\hline & $\mathbf{J}$ & $\mathbf{X 2}$ & $\mathbf{W 1}$ & $\mathbf{F}$ & $\mathbf{H 1}$ & $\mathbf{M}$ & $\mathbf{M P}$ & other \\
\hline WT & $-.389^{* *}$ & -0.211 & $.270^{*}$ & $-.396^{* *}$ & $.444^{*}$ & 0.103 & $-.377 * *$ & 0.012 \\
DO & $.362^{* *}$ & 0.24 & -0.173 & $.407 * *$ & $-.353^{* *}$ & -0.159 & $.257 *$ & -0.148 \\
pH & -0.123 & -0.071 & -0.142 & 0.019 & -0.047 & 0.033 & 0.054 & 0.112 \\
Cond & -0.044 & -0.121 & -0.107 & $.262^{*}$ & -0.052 & 0.021 & -0.219 & -0.154 \\
COD & 0.031 & 0.123 & -0.223 & 0.223 & -0.245 & -0.108 & $.265 *$ & 0.153 \\
$\mathrm{NH}_{4}{ }^{-}-\mathrm{N}$ & -0.21 & -0.151 & -0.088 & -0.147 & 0.046 & -0.044 & -0.103 & -0.159 \\
TN & 0.001 & 0.049 & 0.103 & 0.01 & -0.088 & -0.03 & 0.057 & $.375^{* *}$ \\
TP & 0.101 & -0.246 & 0.122 & 0.065 & -0.091 & -0.12 & -0.05 & $-.280^{*}$ \\
SD & -0.158 & -0.02 & $-.264 *$ & -0.115 & -0.077 & 0.226 & 0.153 & 0.146 \\
\hline
\end{tabular}

$* * p<0.01 ; * p<0.05$ 


\section{Discussion}

\section{Temporal succession of phytoplankton functional groups}

Phytoplankton community structure responds to trophic and spatio-temporal gradient through changes in species composition and quantitative ecological traits such as biomass, species richness, and diversity (Watson et al., 1997). Since the concept of functional group was proposed, on account of functional group has high potential as an indicator of variation in limnological conditions, people began to use this new method to reflect and monitor water quality. Our results showed the temporal and spatial environmental changes of the lake ecosystem and the response of phytoplankton functional groups to this environmental heterogeneity. In such a special cold area, high alkalinity, turbidity and eutrophication water environment, the most important thing to be concerned about was the succession process of phytoplankton functional groups.

The same population is maintained when the extent of environmental parameter does not exceed the morphological adaptative capacity of that single population; if environmental changes are strong enough, species replacement takes place offering further adaptation at a higher organization level (Fonseca and de M. Bicudo, 2008). In the investigation of the time succession characteristics of phytoplankton functional groups in Hulun Lake, temperature plays a decisive role in the change of environment. We found that phytoplankton functional groups biomass was dominated by chlorophyta (group X2/J) in spring (May) corresponding to relatively low temperature (16.27C) and high nutrients. Group X2, represented by Chlamydomonas ovalis and Chlamydomonas globosa. According to the report (Tian et al., 2018), it was mainly dominant during seasons with high concentrations of total photosynthesis and total nitrogen. Because of their small size, rapid reproduction and relatively high surface-volume ratio, they can rapidly absorb nutrients from the surrounding environment for growth and reproduction (Jones, 2000). Flagella also allowed vertical migration between water layers with optimal light conditions and nutrient concentrations, which further enhanced the group's competitiveness in the month when light are not very abundant (Jansson et al., 1996; Tian et al., 2018). In addition, group X2 was also very sensitive to filter feeding. Owing to the content of nitrogen and phosphorus in Hulun Lake exceeds the standard seriously, lead directly to a significant reduction of large filter feeding zooplankton in the lake, which is more suitable for the growth of X2 functional group. As for group J, it was mostly found in shallow, high pH, highly enriched lakes (Sommer et al., 1986; Padisák et al., 2009). The advantage position of two functional groups at the same time indicates that the eutrophication is very serious in the lake, which has become the most direct flashpoint of cyanobacteria bloom. The same situation occurred before the cyanobacteria boom in Xiangxi Bay (Wang et al., 2011) in July, the biomass of functional group J remained high during the investigation. In summer (June/July and August) cyanobacteria (mainly group H1/M) took over the dominant position gradually which also resulting in the cyanobacteria bloom in the lake. Anabaena circalinalis and Microcystis are the two main culprits for the cyanobacteria boom in Hulun Lake, which belongs to group $\mathrm{H} 1$ and $\mathrm{M}$ respectively, dominated in summer. Group H1, which was suitable for living in the water environment with low nitrogen content, eutrophication and stratification. Group M, growing in small and medium-sized lakes with rich to super nutrition, low light tolerance and sensitivity to disturbance. As the main functional group causing cyanobacteria bloom, they have been reported in many reservoirs and lakes (Varol, 2019; Yao et al., 2020; Jin et al., 2020). In eutrophic lakes, cyanobacteria tend to dominate in the season with the 
highest temperature due to their optimal growth temperature (Paerl, 1988; Nalewajko and Murphy, 2001; Yang et al., 2009). In the meanwhile, increased WT will decrease the surface water viscosity, which can accelerate the sinking of large immovable species. Owing to cyanobacteria have so good ability to adjust their buoyancy that dominate the communities (O'Neil et al., 2012), they can also reduce the biomass of other phytoplankton species through an allelopathic mechanism (Sarma et al., 2005), which may account for their advantages in freshwater ecosystems. In addition to the appropriate temperature and eutrophic water conditions, light also played a critical role in the cyanobacteria bloom. In the study of the transformation mechanism of Anabaena and Microcystis (Wang, 2017), we found that compared with microcystis, Anabaena needed more light energy in the growth process, which is also the vital reason why group $\mathrm{M}$ was dominant in August while group H1 was dominant in June and July. Autumn (September and October) caming as the temperature droping rapidly to $10.59^{\circ} \mathrm{C}$ on average, chlorophyta (group X2/J) and bacillariophyta (group MP) which adapted to lower temperature occupied a dominant position.

The predominant functional groups demonstrated strong seasonal variations which showed a trend of $\mathrm{J} / \mathrm{X} 2$ (May) $\rightarrow \mathrm{H} 1 / \mathrm{X} 2$ (June) $\rightarrow \mathrm{H} 1 / \mathrm{J}($ July) $\rightarrow \mathrm{M} / \mathrm{H} 1$ (August) $\rightarrow$ $\mathrm{X} 2 / \mathrm{J}($ September $) \rightarrow \mathrm{J} / \mathrm{X} 2 / \mathrm{MP}($ October $)$. The whole succession mechanism not only accords with the PEG model of freshwater ecosystem, but also shows the same succession trend with the groups in Dali Lake, which is also a water area with high alkalinity in the cold region (Ma et al., 2019). For the special water body like Hulun Lake, what we concerned about is the distinctive feature. As can be seen, group H1 and M were the main culprits for the cyanobacteria bloom in the lake which had significant difference with groups in tropical areas. Moreover, cyanobacteria bloom in June and July was mainly dominated by functional group H1, while in August, it was dominated by group M. From the perspective of biomass changes, the cyanobacteria bloom in Hulun Lake began in June, reached its peak in July and August, basically disappeared in September. The duration of bloom in Hulun Lake was significantly shorter than that of other tropical and subtropical regions. The unique phytoplankton succession mechanism and characteristics of cyanobacteria bloom also showed that the constantly fluctuating physical and chemical factors in the water played a vital role in regulating the distribution of phytoplankton.

\section{Phytoplankton functional groups and their correlation with environmental factors}

Results of previous studies have showed that the spatiotemporal pattern of diversity indices of functional groupings is dependent on the environmental factors (Becker et al., 2010; Weithoff et al., 2015). Understanding how environmental variations affect the biodiversity and succession of phytoplankton is a key challenge (Wang et al., 2020). Generally speaking, the environmental factors that dominate the distribution of phytoplankton functional groups in different regions are quite different. Transparency, salinity and chlorophyll a are considered to be crucial factors affecting the distribution of phytoplankton in tropical areas such as Li'an Bay (Wang et al., 2016a) in Hainan Province. The results of investigation in subtropical areas such as Baihua reservoir (Chen et al., 2018) in Guizhou Province have showed that nutrients are the main factors affecting the distribution of phytoplankton functional groups. Studies in temperate regions such as the Nanshui reservoir in Guangdong Province have found that nutrients, water stability and transparency are the main environmental factors affecting the dynamic changes of phytoplankton functional groups (Huang et al., 2014). However, it is obviously different from other areas in the cold region with notable water temperature change. The main 
environmental factor affecting the distribution of phytoplankton functional groups in the cold region is water temperature (Cao et al., 2019).

In the RDA correlation analysis of phytoplankton functional groups and water environmental factors in Hulun Lake, it can be seen that water temperature (WT) has the highest correlation, which is consistent with the research results of other cold water areas (Lin et al., 2017; Yu et al., 2008; Wu et al., 2015). Temperature can directly affect the growth of phytoplankton by controlling the intensity of enzymatic reaction or respiration of photosynthesis, by controlling the solubility, dissociation degree or decomposition rate of various nutrients in water affects the growth of phytoplankton indirectly (Song and Yu, 2009; Peng et al., 2009; Wu et al., 2010). Group F, J and MP were negatively correlated with temperature, while group $\mathrm{H} 1$ and $\mathrm{M}$ just on the contrary. Therefore, in spring and autumn with lower temperature, groups $\mathbf{J}$ and MP are more likely to gain dominant position in resource competition, while group $\mathrm{H} 1$ and $\mathrm{M}$ take advantage of the high temperature environment in summer to be dominant species in water area. Once their biomass starts to increase rapidly with the rise of water temperature, a large area of cyanobacteria bloom begins to form, which will not only make the dissolved oxygen content in water drop rapidly, but also have many negative effects on the water quality (Elliott et al., 2006; Edwards et al., 2016).

Dissolved oxygen (DO) is also a pivotal factor affecting the distribution of phytoplankton, which plays a vital role in maintaining the ecological security of the water body. Phytoplankton are the suppliers of dissolved oxygen in water, but if phytoplankton increase excessively, it will also become the booster of dissolved oxygen reduction (Zhao et al., 2011). The formation of cyanobacteria bloom in summer by functional groups $\mathrm{M}$ and $\mathrm{H} 1$ is a distinct proof of this view. Therefore, there is a significant negative correlation between group M, H1 and dissolved oxygen in RDA analysis diagram, which is consistent with the conclusion on Dianshan Lake (Yang et al., 2018). Moreover, the higher the dissolved oxygen content, the better the water quality. In Pearson correlation analysis, it can be seen that there is a significant positive correlation between dissolved oxygen and functional group F, which is represented by stichcoccus bacillaris and oocystis elliptica of Chlorophyta, suitable for growing in even and clear deep-water lakes and is very sensitive to high turbidity. It also shows that dissolved oxygen plays a significant role in phytoplankton.

The effect of nutrients on phytoplankton functional groups in eutrophic waters has been received considerable attention. For Hulun Lake, in recent years, due to the impact of climate and human activities, coupled with a large number of surface runoff and hay into the lake, the content of total nitrogen and total phosphorus in the lake has been increasing. With the continuous increase of evaporation and decline of water level, water in lake cannot be circulated effectively, the nutrients, salts and organic pollutants in the lake have been concentrated continuously. Up to now, the water quality of Hulun Lake has been polluted by different degrees of eutrophication. RDA analysis showed that TN and TP were one of the most significant factors affecting the distribution of phytoplankton functional groups in Hulun Lake which is the same as that of other eutrophic cyanobacteria bloom area (Wang et al., 2016b, 2018; Xia et al., 2019). However, there was no significant correlation between TN/TP and H1, the main functional group causing the cyanobacteria bloom in Hulun Lake. On the one hand, the correlation between group $\mathrm{H} 1$ and nutrients is closely related to the degree of cyanobacteria bloom in the lake. Generally speaking, the high content of nutrients in water is a vital factor to induce cyanobacteria bloom. Phosphorus content often appears as an important limiting factor. 
The measuration of total phosphorus includes dissolved phosphorus and granular phosphorus. In the process of digesting, the granular phosphorus contained in cyanobacteria itself will be determined as part of the total phosphorus content. When the cyanobacteria bloom is severe, the proportion of particulate phosphorus in the total phosphorus content of cyanobacteria is very high. Therefore, when monitoring Hulun Lake in 2015, due to the serious outbreak of cyanobacteria, there is a significant positive correlation between nutrients and group H1. However, the bloom in 2018 is more slight compared with 2015, so the proportion of cyanobacteria to particulate phosphorus is relatively low in the total phosphorus content, there is no significant positive correlation. On the other hand, this result is consistent with Liebig Law of Minimum, which states that any specific factor below the minimum required by a certain organism is the fundamental factor determining the survival and distribution of that organism. The results showed that when the concentrations of total phosphorus and total nitrogen reached $0.03 \mathrm{mg} / \mathrm{L}$ and $0.60 \mathrm{mg} / \mathrm{L}$ respectively, there is a trend of cyanobacteria bloom in the lake. Anabaena can fix nitrogen in the air, so the threshold of total nitrogen is much lower. The average value of TN and TP in Hulun Lake during the whole investigation period (TN: 2.05; TP: 0.21) is far beyond this threshold, which provides sufficient nutrients for the growth of phytoplankton, especially cyanobacteria. Therefore, TN and TP are not the main limiting factors for the outbreak of cyanobacteria in Hulun Lake.

Chemical oxygen demand (CODcr) can measure the content of organic matter in water scientifically, reflect the degree of water pollution by reducing substances directly. The water area of Hulun Lake is not only polluted by external organic pollutants, but also polluted by the release of organic substances in the sediment. Some studies have shown that diatoms are more suitable to grow in the environment with higher chemical oxygen demand than other phytoplankton. Pearson correlation analysis in this study indicates that CODcr is positively correlated with group MP which is consistent with the conclusion of Chai (Chai et al., 2020).

Transparency (SD) is a major indicator of water cleanliness, which can reflect the state of water intuitively. Hulun Lake not only has the emergence of cyanobacteria bloom, but also due to the lack of large aquatic plants on the lake, is unable to play a role in purifying water quality, leading to low transparency in the lake as a whole. The results of Pearson correlation analysis showed that there was a significant negative correlation between the transparency and the biomass of W1 functional group, which was also consistent with the characteristics of W1 suitable for growing in sewage. Moreover, for the water area with high alkalinity, calcium ion will be consumed and precipitated, resulting in the turbidity of the water in Hulun Lake. This is also the reason why transparency and $\mathrm{pH}$ are significantly negatively correlated, which is the same as the monitoring result of Hulun Lake in 2017 (Pan et al., 2017).

\section{$Q$ index}

Q index was originally developed to assess ecological status of different water types without geographic limitations (Padisák et al., 2009). So far, many scholars have successfully used $\mathrm{Q}$ index to evaluate the ecological status in different regions. For instance, Crossetti and de M. Bicudo (2008) have successfully applied this index in an urban tropical reservoir, Becker et al. (2009) have used Q index in a subtropical watersupply reservoir. It can also be used in assessing the water quality of lake (Pasztaleniec and Poniewozik, 2010). In this study, through the calculation of $Q$ index by using 
phytoplankton functional group, we have successfully indicated the water quality of Hulun Lake from the perspective of time and space.

From the temporal aspect, the ecological status was correspondent with the cyanobacteria bloom process. During the whole investigation period, the ecological status in the lake took on a declining and followed improving trend, which was the same as that in the process of cyanobacteria bloom in Xiangxi River (Wang et al., 2011). From June, the biomass of $\mathrm{H} 1$ functional group reached the highest value, the lake began to show a trend of cyanobacteria bloom, Q index fell to "tolerable" level with the worst water quality in the whole investigation. In July and August, with the gradual increase of temperature, a large area of cyanobacteria began to break out in the lake under the joint efforts of group $\mathrm{H} 1$ and $\mathrm{M}$, the water quality was also worrying. The best water quality occured in October, the biomass of MP functional group increased due to the decreased of temperature, water quality states rose once more to a "medium" ecological level. As to the spatial pattern, there were obvious differences between ten sites in Hulun Lake. On the whole, the worst average water quality points appeared in site $9^{\#}$ and $5^{\#}$. In August, site $2^{\#}$ and $10^{\#}$ were the sampling points with the lowest $Q$ index value, which was also having the worst water quality. All of these could be related to the cyanobacteria bloom in the lake and the large increase of biomass of $\mathrm{H} 1$ and $\mathrm{M}$ functional groups, which had been reported in the research of Silva and da Costa (2015).

It is concluded that this method of using $\mathrm{Q}$ index to assess the ecological status in a eutrophic seriously, with cyanobacteria blooming lake is available. It has been showed a high sensitivity to changes in species composition and functional groups. Revealing itself as a suitable tool for monitoring the water quality in the studied area. However, it remains to be further studied whether the other indicators for evaluating water quality and eutrophication are the same as those indicated by $\mathrm{Q}$ index.

\section{Conclusion}

This study shows that the monitoring method of phytoplankton functional group is also applicable in the cold area with high alkalinity and eutrophication, and it is also a favorable method to monitor the phenomenon of cyanobacteria bloom in the lake. The $\mathrm{Q}$ index emerged as the times require can reflect the water quality in the lake accurately. During the study period, the time succession of phytoplankton functional groups was obvious which showed the variation trend of $\mathrm{J}+\mathrm{X} 2$ (May) $\rightarrow \mathrm{H} 1+\mathrm{X} 2$ (June) $\rightarrow \mathrm{H} 1+\mathrm{J}$ (July) $\rightarrow \mathrm{M}+\mathrm{H} 1$ (August) $\rightarrow \mathrm{X} 2+\mathrm{J}$ (September) $\rightarrow \mathrm{J}+\mathrm{X} 2+\mathrm{MP}$ (October). The cyanobacteria bloom in lake began in June, reached its peak in July and August, basically disappeared in September. The main phytoplankton functional groups causing cyanobacteria bloom in the lake were $\mathrm{H} 1$ and $\mathrm{M}$. It also turned out that water temperature, dissolved oxygen, total phosphorus and total nitrogen were the most significant environmental factors affecting the distribution of phytoplankton functional groups in Hulun Lake studied by using RDA and Pearson correlation analysis. Meanwhile, the persistently high content of nitrogen and phosphorus in Hulun Lake provides rich nutrients for phytoplankton. Therefore, total nitrogen and total phosphorus are not the main limiting factors of cyanobacteria bloom in Hulun Lake.

Our research has provided a new idea for the study of cyanobacteria bloom and water quality monitoring in cold regions. However, how to eliminate and control severe cyanobacteria bloom is the most significant thing we need to pay attention to currently. Our team has also been monitoring the population dynamics of zooplankton in this area, 
particularly the large filter-feeding zooplankton, with a view to long-term monitoring to find a new approach of controlling cyanobacteria bloom by means of plankton. Further studies should establish a more intuitive connection between phytoplankton especially Cyanobacteria, water environmental factors and zooplankton bases on data collected over a longer period with more frequent sampling and analysis in different regions, to evaluate the impact of top-down effects on phytoplankton and cyanobacteria bloom. Further analyze, solve and prevent the phenomenon of cyanobacteria bloom.

Acknowledgements. We thank to the leaders and workers from Hulun Lake for their assistance and support during field sampling work. This study was supported by the Fundamental Research Funds for the Central Universities (2572018BE03) and National Key Research and Development Program of China (Grant No.2016YFC0500406).

\section{REFERENCES}

[1] Becker, V., Huszar, V. L. M., Crossetti, L. O. (2009): Responses of phytoplankton functional groups to the mixing regime in a deep subtropical reservoir. - Hydrobiologia 628: 137-151.

[2] Becker, V., Caputo, L., Ordóñez, J., Marcé, R., Armengol, J., Crossetti, L. O., Huszar, V. L. M. (2010): Driving factors of the phytoplankton functional groups in a deep Mediterranean reservoir. - Water Research 44: 3345-3354.

[3] Belletti, B., Rinaldi, M., Bussettini, M., Comiti, F., Gurnell, A. M., Mao, L., Nardi, L., Vezza, P. (2017): Characterising physical habitats and fluvial hydromorphology: A new system for the survey and classification of river geomorphic units. - Geomorphology 283: 143-157.

[4] Birk, S., Bonne, W., Borja, A., Brucet, S., Courrat, A., Poikane, S., Solimini, A., van de Bund, W., Zampoukas, N., Hering, D. (2012): Three hundred ways to assess Europe's surface waters: an almost complete overview of biological methods to implement the water framework directive. - Ecological Indicators 18: 31-41.

[5] Camp, J., Flo, E., Vila, M., Arin, L., Reñé, A., Sampedro, N., Manzanera, M., Garcés, E. (2015): Pros and cons of biological quality element phytoplankton as a water-quality indicator in the NW Mediterranean Sea. - Experiences from Ground, Coastal and Transitional Water Quality Monitoring 43: 135-160.

[6] Cao, W. Z., Sun, Y. F., Yang, S., Gai, Y. J., Liu, J. H., Fan, Y. W. (2019): Study on the community structure and diversity of phytoplankton in Kulipao Lake of Daqing. Ecological Science 38: 206-211. (in Chinese).

[7] Chai, R., Feng, J., Chen, B. J., Xia, B., Sun, X. M., Wang, X. X., Chen, J. F., Cui, Z. G., $\mathrm{Qu}, \mathrm{K}$. M. (2020): Seasonal variations in the phytoplankton community structure and their environmental impact factors in the offshore area of Laoshan, Qingdao. - Progress in Fishery Sciences 41: 21-30. (in Chinese).

[8] Chen, Y. W., Qin, B. Q., Teubner, K., Dokulil, M. T. (2003): Long-term dynamics of phytoplankton assemblages: Microcystis-domination in Lake Taihu, a large shallow lake in China. - Journal of Plankton Research 25: 445-453.

[9] Chen, Q., Li, Q. H., Hu, Y. M., Zhu, C. C., He, Y., Zhang, H. J. (2018): Spatial and temporal distribution characteristics of phytoplankton functional groups and their influencing factors in Baihua Reservoir, Guizhou Province. - Research of Environmental Sciences 31: 12651274. (in Chinese).

[10] Chuai, X. M., Ding, W., Chen, X. F., Wang, X. L., Miao, A. J., Xi, B. D., He, L. S., Yang, L. Y. (2011): Phosphorus release from cyanobacterial blooms in meiliang bay of Lake Taihu, China. - Ecological Engineering 37: 842-849. 
[11] Costa, L. S., Huszar, V. L. M., Ovalle, A. R. (2009): Phytoplankton functional groups in a tropical estuary: hydrological control and nutrient limitation. - Estuaries and Coasts 32: 508-521.

[12] Crossetti, L. O., de M. Bicudo, C. E. (2008): Phytoplankton as a monitoring tool in a tropical urban shallow reservoir (Garças Pond): the assemblage index application. Hydrobiologia 610: 161-173.

[13] Edwards, K. F., Thomas, M. K., Klausmeier, C. A., Litchman, E. (2016): Phytoplankton growth and the interaction of light and temperature: A synthesis at the species and community level. - Limnology and Oceanography 61: 1232-1244.

[14] Elliott, J. A., Jones, I. D., Thackeray, S. J. (2006): Testing the sensitivity of phytoplankton communities to changes in water temperature and nutrient load, in a temperate lake. Hydrobiologia 559: 401-411.

[15] Fonseca, B. M., de M. Bicudo, C. E. (2008): Phytoplankton seasonal variation in a shallow stratified eutrophic reservoir (Garças Pond, Brazil). - Hydrobiologia 600: 267-282.

[16] Hillebrand, H., Dürselen, C. D., Kirschtel, D., Pollingher, U., Zohary, T. (1999): Biovolume calculation for pelagic and benthic microalgae. - Journal of Phycology 35: 403424.

[17] Huang, C., Yue, Q., Shi, Y. K., Li, H. J., Xu, X. Y., Chen, Y. F., Qiu, J. T. (2014): Characteristics of phytoplankton functional groups in main reservoirs for large and medium sized drinking water supply in Shaoguan, China. - Ecological Science 33: 282-287. (in Chinese).

[18] Isabwe, A., Yang, J. R., Wang, Y. M., Liu, L. M., Chen, H. H., Yang, J. (2018): Community assembly processes underlying phytoplankton and bacterioplankton across a hydrologic change in a human-impacted river. - Science of the Total Environment 630: 658-667.

[19] Jansson, M., Blomqvist, P., Jonsson, A., Bergström, A. K. (1996): Nutrient Limitation of Bacterioplankton, Autotrophic and Mixotrophic Phytoplankton, and Heterotrophic Nanoflagellates in Lake Örträsket. - Limnology and Oceanography 41: 1552-1559.

[20] Jin, Y., Yu, R. H., Zhang, Z. Z., Zhang, Q., Li, M. X., Cao, Z. X., Wu, L. H., Hao, Y. L. (2020): Spatiotemporal variability of phytoplankton functional groups in a shallow eutrophic lake from cold, arid regions. - Environmental Monitoring and Assessment 192: 371.

[21] Jones, R. (2000): Mixotrophy in planktonic protists: an overview. - Freshwater Biology 45: 219-226.

[22] Latinopoulos, D., Ntislidou, C., Kagalou, I. (2020): Relationships of environmental conditions and phytoplankton functional groups in a new re-constructed shallow lentic system in draught conditions. - Ecohydrology and Hydrobiology 20: 369-381.

[23] Liao, N., Li, H., You, L. H., Chen, M., Zhang, L. L., An, R. D., Li, J., Zhang, Y. W. (2020): Succession of phytoplankton functional groups and driving variables in a young canyon reservoir. - International Journal of Environmental Science and Technology 1: 1-14.

[24] Lin, K. X., Wang, X., Wang, Y., Zhou, J., Liu, L. S., Zhu, Y. Z., Xia, Y. (2017): Composition and influencing factors of algal functional groups in Jingpo Lake. - Research of Environmental Sciences 30: 520-528. (in Chinese).

[25] Ma, C. X., Mwagona, P. C., Yu, H. X., Sun, X. W., Liang, L. Q., Al-Ghanim, K. A., Mahboob, S. (2019): Spatial and temporal variation of phytoplankton functional groups in extremely alkaline Dali Nur Lake, North China. - Journal of Freshwater Ecology 34: 91105.

[26] MEP (2002): China national environmental quality standards for surface water. - GB38382002. (in Chinese).

[27] Myers, N., Mittermeier, R. A., Mittermeier, C. G., da Fonseca, G. A. B., Kent, J. (2000): Biodiversity hotspots for conservation priorities. - Nature 403: 853-858.

[28] Nalewajko, C., Murphy, T. P. (2001): Effects of temperature, and availability of nitrogen and phosphorus on the abundance of Anabaena and Microcystis in Lake Biwa, Japan: an experimental approach. - Limnology 2: 45-48. 
[29] O'Neil, J. M., Davis, T. W., Burford, M. A., Gobler, C. J. (2012): The rise of harmful cyanobacteria blooms: the potential roles of eutrophication and climate change. - Harmful Algae 14: 313-334.

[30] Padisák, J., Borics, G., Grigorszky, I., Soróczki-Pintér, É. (2006): Use of phytoplankton assemblages for monitoring ecological status of lakes within the water framework directive: the assemblage index. - Hydrobiologia 553: 1-14.

[31] Padisák, J., Crossetti, L. O., Naselli-Flores, L. (2009): Use and misuse in the application of the phytoplankton functional classification: a critical review with updates. - Hydrobiologia 621: 1-19.

[32] Paerl, H. W. (1988): Nuisance phytoplankton blooms in coastal, estuarine, and inland waters. - Limnology and Oceanography 33: 823-847.

[33] Pan, H., Liu, Y. R., Ma, C. X. (2017): Characteristics and physical factors of cyanobacteria outbreak in northern cold region inland alkaline water. - Journal of Northeast Forestry University 45: 79-83. (in Chinese).

[34] Pasztaleniec, A., Poniewozik, M. (2010): Phytoplankton based assessment of the ecological status of four shallow lakes (Eastern Poland) according to water framework directive-a comparison of approaches. - Limnologica-Ecology and Management of Inland Waters 40: 251-259.

[35] Peng, F., Huang, Y. L., Zhang, Y. F., Xue, C. A., Zhi, L. (2009): Character of algae variety and distribution of source water. - Water Technology 3: 1-4. (in Chinese).

[36] Reynolds, C. S., Huszar, V., Kruk, C., Naselli-Flores, L., Melo, S. (2002): Towards a functional classification of the freshwater phytoplankton. - Journal of Plankton Research 24: 417-428.

[37] Reynolds, C. S. (2006): The Ecology of Phytoplankton: Ecology, Biodiversity and Conservation. - Cambridge University Press, Cambridge, UK.

[38] Rose, V. J., Forney, W. M., Norton, R. A., Harrison, J. A. (2019): Catchment characteristics, water quality, and cyanobacterial blooms in Washington and Oregon Lakes. - Lake and Reservoir Management 35: 51-63.

[39] Sarma, S. S. S., Nandini, S., Gulati, R. D. (2005): Life history strategies of cladocerans: comparisons of tropical and temperate taxa. - Hydrobiologia 542: 315-333.

[40] Shang, S. (2017): Study on influence of temperature and light on the growth of several dominant algae in Yangtze river estuary. - Shanghai Normal University (in Chinese).

[41] Silva, A. P. C., da Costa, I. A. S. (2015): Biomonitoring ecological status of two reservoirs of the brazilian semi-arid using phytoplankton assemblages (Q index). - Acta Limnologica Brasiliensia 27(1): 1-14.

[42] Solis, M., Pawlik-Skowrońska, B., Adamczuk, M., Kalinowska, R. (2018): Dynamics of small-sized Cladocera and their algal diet in lake with toxic cyanobacterial water blooms. - Annales de Limnologie, International Journal of Limnology 54: 6.

[43] Sommer, U., Gliwicz, Z. M., Lampert, W. I., Duncan, A. (1986): The PEG-model of seasonal succession of planktonic events in freshwaters. - Archiv für Hydrobiologie 106: 433-471.

[44] Song, C., Yu, H. X. (2009): Phytoplankton diversity in Jingpo Lake and water quality evaluation. - Journal of Northeast Forestry University 37: 40-42. (in Chinese).

[45] Tian, C., Hao, D. P., Pei, H. Y., Doblin, M. A., Ren, Y., Wei, J. L., Feng, Y. W. (2018): Phytoplankton functional groups variation and influencing factors in a shallow temperate lake. - Water Environment Research 90: 510-519.

[46] Varol, M. (2019): Phytoplankton functional groups in a monomictic reservoir: seasonal succession, ecological preferences, and relationships with environmental variables. Environmental Science and Pollution Research 26: 20439-20453.

[47] Wang, L., Cai, Q. H., Tan, L., Kong, L. H. (2011): Phytoplankton development and ecological status during a cyanobacterial bloom in a tributary bay of the Three Gorges Reservoir, China. - Science of the Total Environment 409: 3820-3828. 
[48] Wang, J. J., Pan, F. Y., Soininen, J., Heino, J., Shen, J. (2016): Nutrient enrichment modifies temperature-biodiversity relationships in large-scale field experiments. - Nature Communications 7: 13960.

[49] Wang, C. C., Chen, X., Ban, G. Y., Tang, M. (2016a): Characteristics of phytoplankton communities and their response to environmental factors at Li'an Lagoon in Hainan. Journal of Tropical Biology 7: 177-184. (in Chinese).

[50] Wang, H., Yang, S. P., Fang, S. Z., Yu, F. C., Feng, W. B., Liu, L. P. (2016b): Canonical correspondence analysis of relationship between characteristics of phytoplankton community and environmental factors in Dianchi Lake. - China Environmental Science 36: 544-552. (in Chinese).

[51] Wang, X. L. (2017): The spatial and temporal turnover between Microcystis and Dolichospermum in Lake Chaohu. - Yangzhou university (in Chinese).

[52] Wang, X. L., Zhang, M., Yin, J. (2018): Composition and influential factors of phytoplankton function groups in Lake Chaohu. - Journal of Lake Sciences 30: 431-440. (in Chinese).

[53] Wang, H., Zhao, D. D., Chen, L., Giesy, J. P., Zhang, W. Z., Yuan, C. B., Ni, L. Y., Shen, H., Xie, P. (2020): Light, but not nutrients, drives seasonal congruence of taxonomic and functional diversity of phytoplankton in a eutrophic highland lake in China. - Frontiers in Plant Science 11: 179.

[54] Watson, S. B., Mccauley, E., Downing, J. A. (1997): Patterns in phytoplankton taxonomic composition across temperate lakes of differing nutrient status. - Limnology and Oceanography 42: 487-495.

[55] Weithoff, G., Rocha, M. R., Gaedke, U. (2015): Comparing seasonal dynamics of functional and taxonomic diversity reveals the driving forces underlying phytoplankton community structure. - Freshwater Biology 60: 758-767.

[56] Wu, H. X., Wang, Q., Cai, Z., Xue, J. Z., Li, Y. X., Huang, S. L. (2010): Studying the phytoplankton of Hongshan Reservoir in Jimunai. - Journal of Hydroecology 3: 50-54. (in Chinese).

[57] Wu, A. Q., Guo, N., Qin, X. B. (2015): Seasonal variation of phytoplankton functional groups and their relationship with environmental factors in a typical cold regions wetland. - Acta Scientiae Circumstantiae 35: 1341-1349. (in Chinese).

[58] Wu, N. C., Qu, Y. M., Guse, B., Makarevičiūtè, K., To, S., Riis, T., Fohrer, N. (2018): Hydrological and environmental variables outperform spatial factors in structuring species, trait composition, and beta diversity of pelagic algae. - Ecology and evolution 8: 29472961.

[59] Xia, Y. F., Hu, X. D., Xu, J. X., Li, Y. P., Wu, S. S., Wu, P. P. (2019): Seasonal succession of phytoplankton functional group and assessment of water quality in Lake Taihu. - Journal of Lake Sciences 31: 134-146. (in Chinese).

[60] Yang, Z. Y., Li, C. Y., Zhang, S., Sun, B. (2009): Temporal and spatial distribution of chlorophyll-a concentration and the relationships with TN, TP concentrations in Lake Ulansuhai, Inner Mongolia. - Journal of Lake Sciences 21: 429-433. (in Chinese).

[61] Yang, L., Zhang, W., Shang, G. X., Zhang, J. Y., Wang, L. Q., Wei, H. (2018): Succession characteristics of phytoplankton functional groups and their relationships with environmental factors in Dianshan Lake, Shanghai. - Environmental Science 39: 31583167. (in Chinese).

[62] Yang, W., Zhang, F. Y., Sun, Y. C., Zhang, T. T., Huang, Y., Ge, Q., Deng, D. G. (2020): Seasonal succession and influencing factors of phytoplankton functional groups in Lake Nanhu, Huaibei City. - China Environmental Science 40: 3079-3086.

[63] Yao, L. G., Zhao, X. M., Zhou, G. J., Liang, R. C., Gou, T., Xia, B. C., Li, S. Y., Liu, C. (2020): Seasonal succession of phytoplankton functional groups and driving factors of cyanobacterial blooms in a subtropical reservoir in south China. - Water 12: 1167.

[64] Yu, H. X., Qu, C., Ma, C. X. (2008): Correlation between phytoplankton abundance and its environmental factors in Mudan River. - Wetland Science 6: 293-297. (in Chinese). 


$$
-1569 \text { - }
$$

[65] Zhang, M., Zhang, Y. C., Yang, Z., Wei, L. J., Yang, W. B., Chen, C., Kong, F. X. (2016): Spatial and seasonal shifts in bloom-forming cyanobacteria in Lake Chaohu: Patterns and driving factors. - Phycological Research 64: 44-55.

[66] Zhao, H. C., Wang, S. R., Zhao, M., Jiao, L. X., Liu, B., Jin, X. C. (2011): Relationship between the DO and the environmental factors of the water body in Lake Erhai. Environmental Science 32: 1952-1959. (in Chinese).

[67] Zwart, J. A., Solomon, C. T., Jones, S. E. (2015): Phytoplankton traits predict ecosystem function in a global set of lakes. - Ecology 96: 2257-2264. 